\title{
APLIKASI ADMINISTRASI PENGGAJIHAN GURU DAN KARYAWAN ONLINE SMK ARUNG SAMUDRA BANJARMASIN BERBASIS QUICK RESPONSE (QR) KODE
}

\author{
Herry Adi Chandra ${ }^{1)}$, Hoiriyah ${ }^{2)}$, Fakhriani Ekawati ${ }^{3)}$ \\ ${ }^{1}$ Fakultas Teknologi Informasi Universitas Islam Kalimantan Muhammad Arsyad Al Banjari \\ Banjarmasin \\ email: herrysbc@gmail.com \\ ${ }^{2}$ Fakultas Teknologi Informasi Universitas Islam Kalimantan Muhammad Arsyad Al Banjari \\ Banjarmasin \\ email: ihaybjm18@gmail.com \\ ${ }^{3}$ Fakultas Teknologi Informasi Universitas Islam Kalimantan Muhammad Arsyad Al Banjari \\ Banjarmasin \\ email: Fakhrianiekawati@gmail.com
}

\begin{abstract}
Abstrak
Untuk saat ini dalam proses penggajian guru dan karyawan di sekolah masih didominasi dengan cara manual. Kelemahan dari sistem yang sudah ada yaitu sistem tersebut tidak efisien, banyak memakan waktu dalam proses pencatatan dan mengolah proses penggajian. Sehingga penelitian ini bertujuan untuk mengembangkan suatu model yang membuat sebuah aplikasi administrasi penggajian karyawan di SMK Arung Samudra Banjarmasin berbasis Quick Response (Qr) Kode , serta mempermudah dalam mengelola data dan gaji pegawai yang tepat dan akurat. dengan aplikasi ini guru dan karyawan dapat melakukan pengecekan gajih dan honor melalui Quick Response (Qr) Kode yang tertera pada kartu karyawan menggunakan smartphone sebagai pembaca Quick Response (Qr) Kode, sehingga karyawan staf bagian keuangan tidak perlu lagi merekap gajih dan honor secara manual.
\end{abstract}

Kata Kunci : Aplikasi Administrasi, Penggajihan, Quick Response (Qr) Kode

\section{PENDAHULUN}

\subsection{Latar Belakang}

Dengan meningkatnya perkembangan ekonomi dalam segala bidang, maka sudah sewajarnya sekolah mengalami peningkatan disetiap sektor. Dengan adanya peningkatan tersebut sekolah membutuhkan tenaga kerja yang disebut dengan karyawan, yang ditugaskan sekolah untuk melaksanakan kegiatan operasional pada perusahaan tersebut.

Sistem penggajian adalah mengembangkan sekumpulan prosedur yang memungkinkan perusahaan untuk menarik, menahan, dan memotivasi staf serta untuk mengendalikan biaya pembayaran gaji. Dengan prosedur yang disesuaikan dengan kebijakan gaji tiap - tiap organisasi, dan merupakan kebijakan yang dianggap adil. Sistem penggajian dan pengupahan adalah jaringan prosedur yang terdiri dari prosedur pembuatan daftar gaji, prosedur distribusi biaya gaji, dan prosedur pembayaran gaji.

Terkait dengan perkembangan teknologi dan informasi yang semakin pesat, banyak sekolah membutuhkan sistem penggajian yang lebih bisa mengoptimalkan pengolahan data gaji guru dan karyawannya secara cepat dan akurat. Namun belum semua sekolah swasta menerapkan sistem 
penggajian yang terkomputerisasi, sederhana yaitu menggunakan software Ms. Excel sehingga dalam pengolahan datanya mengalami hambatan seperti terjadinya proses kesalahan seperti perhitungan gaji lembur, potongan gaji, gaji pegawai, tunjangan, gaji pokoknya dan laporan gaji harus dihitung dan mengalami proses perhitungan yang berulang - ulang dari tiap karyawannya. Selain itu juga dalam proses absensi kehadiran karyawan sering kali ditemukan data yang tidak akurat dikarenakan perhitungan kehadiran masih dilakukan dengan cara yang manual juga. Apalagi jumlah karyawannya yang banyak berarti membutuhkan pendataan dan perhitungan yang berkali - kali. Hal ini sangat menghambat dalam penyampaian laporan penggajian kepada pemimpin.

\subsection{Rumusan Masalah}

Berdasarkan latar belakang diatas, maka perlu suatu langkah untuk mempermudah guru dan karyawan dapat melakukan pengecekan gajih dan honor melalui kode QR yang tertera pada kartu karyawan menggunakan smartphone sebagai pembaca Quick Response (Qr) Kode, pada SMK Arung Samudra Banjarmasin tersebut maka rumusan masalah yang akan diuraikan pada penelitian ini yaitu bagaimanakah aplikasi sehingga staf bagian keuangan tidak perlu lagi merekap gajih dan honor secara manual dan memberi kemudahan pada sekolah dalam proses perekapan honor dan gajih guru dan karyawan.

\subsection{Tujuan dan Target Luaran}

Tujuan dari penelitian ini adalah membuat suatu sistem aplikasi administrasi guru dan karyawan menggunakan Quick Response (Qr) Kode berbasis online di SMK Arung Samudra Banjarmasin. Adapun manfaat yang diharapkan yaitu : dengan dibuatnya aplikasi ini diharapkan dapat memudahkan staf keuangan mengelola administrasi penggajihan yang terkadang terselip dengan berkas lain dan memberi kemudahan pada sekolah dalam melaksanakan proses belajar-mengajar.

Target luaran yang ingin dicapai oleh kami adalah Penelitian ini bisa masuk Prosiding Jurnal Tegnologia Fakultas Teknologi informasi UNISKA .

\section{METODE PENELITIAN} Tahapan Pengumpulan Data

Untuk memperoleh data yang diperlukan dalam penyusunan penelitian ini dengan menggunakan metode pengumpulan data sebagai berikut:

a. Wawancara atau interview

Wawancara adalah suatu metode yang digunakan untuk memperoleh data dengan cara mengajukan pertanyaanpertanyaan secara langsung. Dalam hal ini kami akan melakukan wawancara secara langsung dengan pihak SMK Arung Samudra Banjarmasin.

b. Pengamatan Langsung atau Observasi. Observasi adalah metode pengumpulan data dengan cara mengamati secara langsung proses penerimaan siswa baru pada SMK Arung Samudra Banjarmasin.

c. Studi Pustaka

Studi pustaka adalah suatu metode pengumpulan data dengan menggunakan buku-buku dan pencarian di internet sebagai bahan referensi dalam penulisan penelitian dan pembuatan sistem.

d. Angket atau kuesioner

adalah teknik pengumpulan data melalui formulir yang berisi pertanyaan-pertanyaan yang diajukan secara tertulis pada seseorang atau sekumpulan orang untuk mendapatkan jawaban atau tanggapan dan informasi yang diperlukan oleh peneliti Penelitian ini menggunakan angket atau kuesioer, daftar pertanyaannya dibuat secara 5 berstruktur dengan bentuk pertanyaan pilihan berganda (multiple choice questions) dan pertanyaan terbuka (open question). Metode ini digunakan untuk memperoleh data tentang ketercapaian 
aplikasi penggajihan karyawan berbasis Qr Kode.

\section{HASIL DAN PEMBAHASAN}

\section{Tahap-Tahap Pembuatan Sistem}

Untuk analisa Sistem dalam membangun sistem informasi ini diperlukan perencanaan yang baik agar dihasilkan sistem yang dapat berjalan optimal.

Tahap perencanaan nya yaitu:

\section{Menentukan tujuan pembuatan aplikasi}

Tujuan pembuatannya adalah membuat suatu sistem aplikasi penggajihan guru dan karyawan menggunakan Quick Response (Qr) Kode berbasis online di SMK Arung Samudra Banjarmasin ini guru dan karyawan dapat melakukan pengecekan gajih dan honor melalui kode QR yang tertera pada kartu karyawan menggunakan smartphone sebagai pembaca kode QR, sehingga karyawan staf bagian keuangan tidak perlu lagi merekap gajih dan honor secara manual.

\section{Langkah yang digunakan}

Langkah yang digunakan dalam penelitian ini adalah merancang dan membuat menggunakan kode QR (QR Code) berbasis android. Berikut rincian langkah-langkah yang dilakukan dalam penelitian ini :

1. Pengajuan proposal

2. Mengakaji ulang teori yang sudah disetujui dan mulai melakukan pengumpulan data premier serta data sekunder untuk penelitian objek lebih lanjut.

3. Melakukan Pengolahan data-data yang sudah dikumpulkan serta menganalisa kebutuhan system untuk mendukung pembuatan aplikasi yang sudah menjadi tujuan.

4. Membuat rancangan serta mempersiapkan sistem aplikasi administrasi penggajihan menggunakan kode QR (QR Code)

5. Melakukan testing dan implementasi system serta Pengujian Alat

6. Melakukan revisi atau perbaikan baik program atau pun alat jika diperlukan

7. Pembuatan laporan penelitan

8. Mengikuti Seminar hasil penelitian

Metode penelitian dalam hal ini meliputi perancangan yang kemudian diwujudkan

Jurnal Ilmiah "Technologia” dengan menggunakan metode One Time Password.

Untuk analisa Kebutuhan sistem aplikasi absensi siswa menggunakan kode QR (QR Code) berbasis web di SMK Arung Samudra Banjarmasin yang akan dibuat nanti diharapkan dapat menyelesaikan masalahmasalah yang dihadapi. Dengan demikian akan membuat beberapa menu guna mempermudah dalam sistem kerja dan agar dapat melangsungkan pengetesan secara baik, serta kebutuhan yang sesuai dengan keinginan.

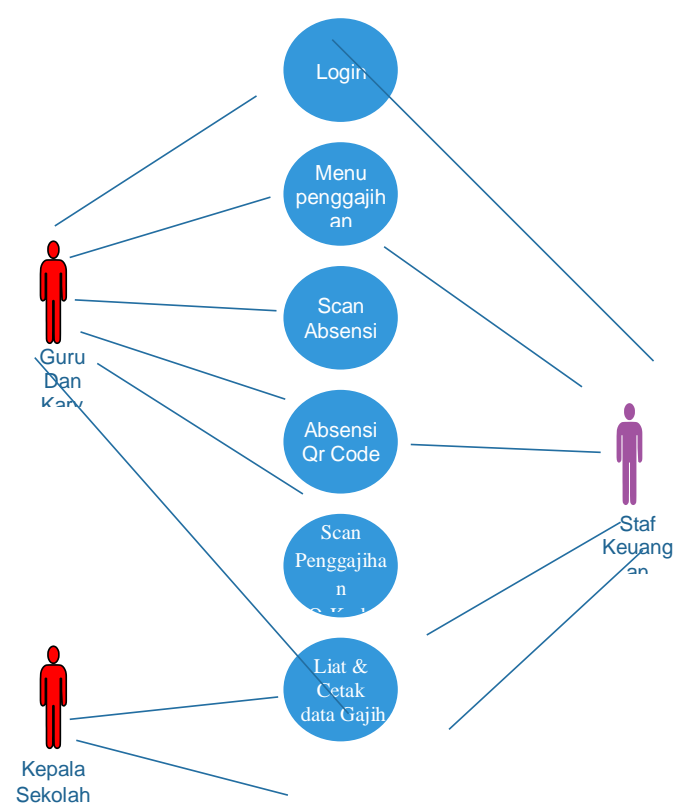

Gambar 1. Usacase Aplikasi Penggajihan

Flowchart merupakan suatu diagram yang menggambarkan alur kerja suatu sistem. Berikut flowmap yang dibuat untuk mendukung aplikasi ini.
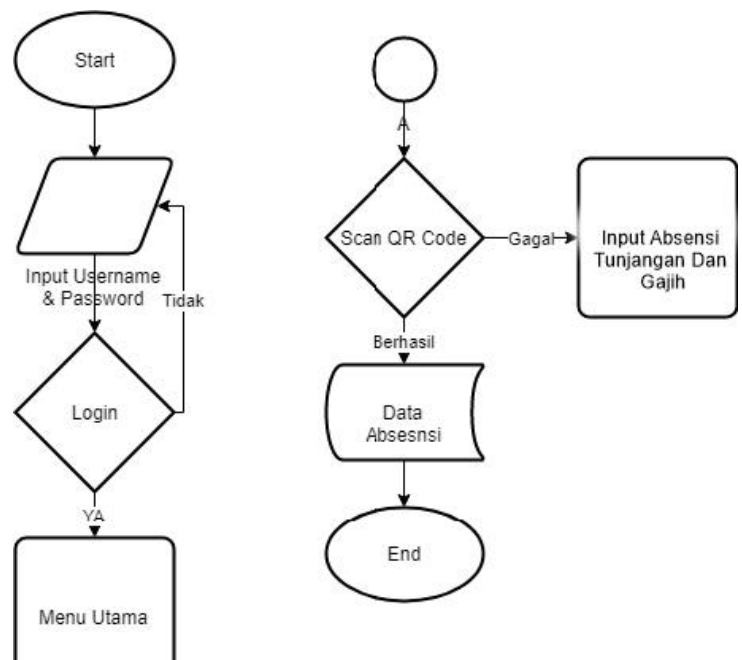
Gambar 2. Flowchart Aplikasi Penggajihan

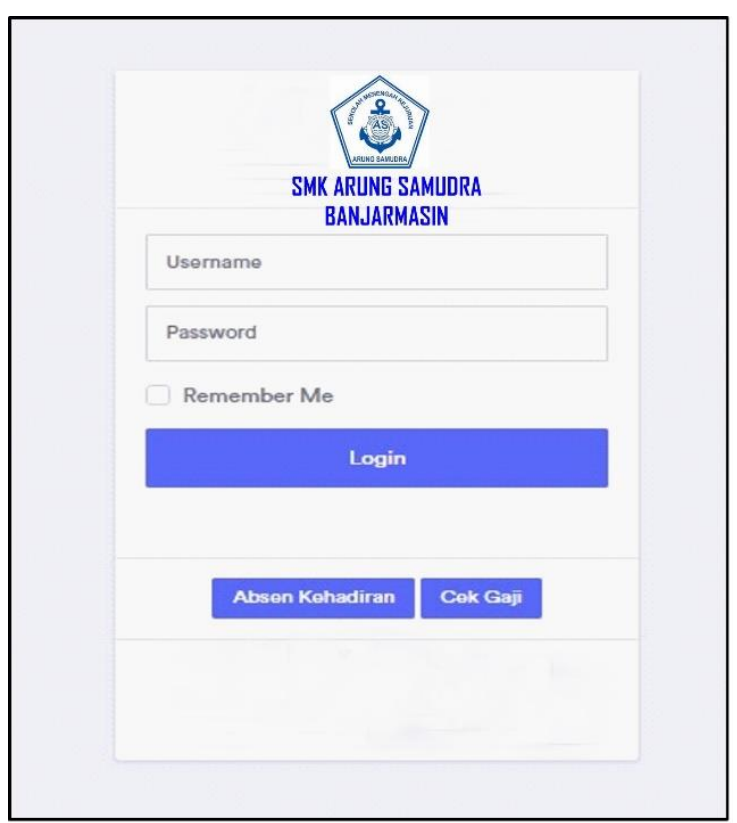

Gambar 3. Tampilan Login Admin Penggajihan

\section{SCAN QR GAJIH KARYAWAN}

Arahkan Kode QR Ke Kameral

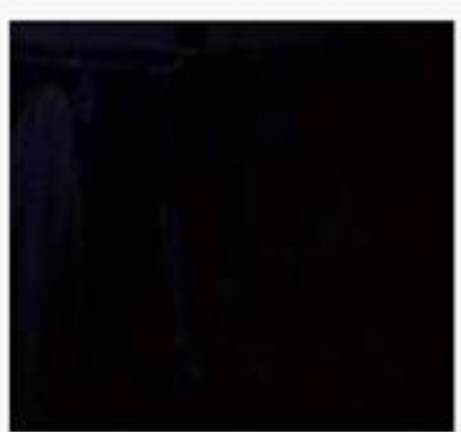

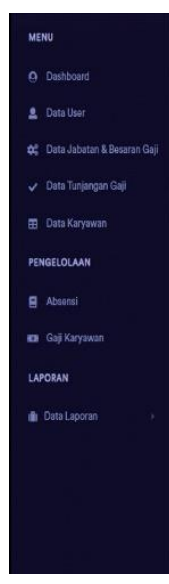

SMK ARUNG SAMUDRA BANJARMASIN

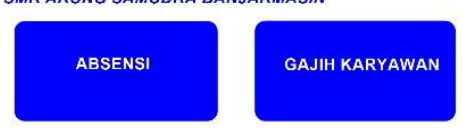

Gambar 5. Tampilan Home Aplikasi Penggajihan

\section{KESIMPULAN}

Dengan Adanya sistem aplikasi administrasi penggajian karyawan di SMK Arung Samudra Banjarmasin berbasis Quick Response (Qr) Kode , serta mempermudah dalam mengelola data dan gaji pegawai yang tepat dan akurat. dengan aplikasi ini guru dan karyawan dapat melakukan pengecekan gajih dan honor melalui Quick Response (Qr) Kode yang tertera pada kartu karyawan menggunakan smartphone sebagai pembaca 
Quick Response (Qr) Kode, sehingga karyawan staf bagian keuangan tidak perlu lagi merekap gajih dan honor secara manual.
Punched Cards to Bar Codes by Benjamin Nelson (Helmers Publishing, ISBN 0911261-12-5, 434 pages)

\section{REFERENSI}

Abdul Kadir (2013). Pengertian MySQL. Tersedia dalam : Buku Pintar Programer Aswin Wibisurya. Pengenalan QR Code. From Binus University School Of Computer Science socs.binus.ac.id/2018/12/15/pengenala n-qr-code/

Badiyanto. 2013. Buku Pintar Framework Yii. Yogyakarta: Mediakom

Jubilee. 2010. Step by Step Ponsel Android. PT Elex Media Komputindo. Jakarta.

Nurhidayat Jajang. dan Irawan Afrianto (2017). Pembangunan Aplikasi Warung Indonesia Di Yangsan Korea Selatan Berbasis Android, 2-3.

Ridwan Fridh Zurriyadi, Santoso Hariyono \& Agung Wiseto P. 2010. Mengamankan Single Identity Number (SIN) Menggunakan QR Code dan Sidik Jari. 2 (2): 17-20.

Rossy Cahyo, Utomo Wiranto Herry \& Wellem Theophilus. 2006. Perancangan dan Implementasi Sistem Informasi Layanan Short

Sutarman. 2009. Pengantar teknologi Informasi. Jakarta : Bumi Aksara

Ir. Sere Saghranie Daulay,M.Si (2018). Hubungan antara QR Code dan Dunia Industri dan Perdagangan

Lines of Communication by Craig Harmon (Helmers Publishing) The Bar Code Book by Roger C. Palmer (Helmers Publishing, ISBN 0-911261-09-5, 386 pages) 